\begin{tabular}{|c|c|c|}
\hline$\bigcup_{\text {INESEG }}$ & $\begin{array}{l}\text { INTERNATIONAL } \\
\text { ENGINEERING, } \\
\text { SCIENCE AND } \\
\text { EDUCATION } \\
\text { GROUP (PUBLISHER) }\end{array}$ & 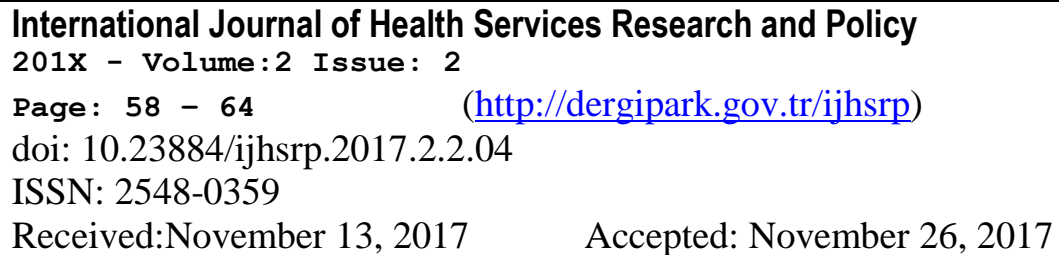 \\
\hline
\end{tabular}

\title{
EXPERIMENTAL INVESTIGATION OF THE EFFECT ON THE CHEMERIN ADIPOKINE AND OBESITY OF PROBIOTIC USE IN OBESE RATS
}

\author{
Mensure Nur Celik ${ }^{* 1}$, Mehtap Unlu Sogut ${ }^{l}$ \\ ${ }^{1}$ Ondokuz Mayis University, Faculty of Health Science, Department of Nutrition and Dietetics, \\ Kurupelit Campus, Samsun/ Turkey \\ *Corresponding author; mensurenur.celik@omu.edu.tr
}

\begin{abstract}
Chemerin is a new chemotactic protein that recently joined the adipokines family. It has been shown to play a role in adipogenesis and energy metabolism, including its role on obesity, Type 2 Diabetes Mellitus (T2DM), metabolic syndrome and cardiovascular diseases. Probiotics may play role in the prevention of obesity by various mechanisms and treatment of many diseases such as T2DM. In this study, we aimed to evaluate the effects of probiotic supplementation of chemerin adipokines on serum levels and obesity markers in obese animal models. For this purpose 3 groups of experimental animals were formed. In the obtained serum samples, the effects of probiotic supplementation on chemerin and leptin level which are indicators of obesity will be examined. Weights of all the rats in the groups were weighed each week to monitor the obesity. The weight gain in the group fed with probiotic

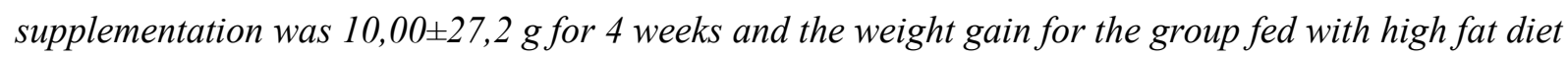

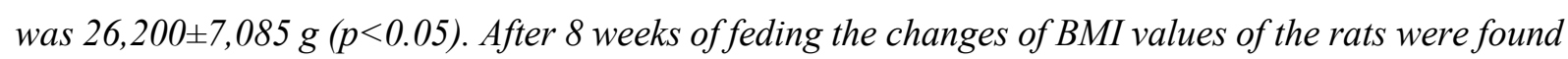
to be statistically significant ( $p<0.05$ ). There was no significant difference between the leptin values of the groups, but the difference between the mean values of the chemerin values after 12 weeks offeeding was found to be statistically significant ( $p<0.05$ ). As a result; this study showed that obese rats reduced the weight gain of probiotic supplementation without calorie restriction, positive effects on BMI and chemerin adipokine serum levels.
\end{abstract}

Key words: chemerin, leptin, obesity 


\section{Introduction}

Chemerin is a new chemotactic protein that recently joined the adipokines family. In 2007, it was discovered that chemerin and its receptor CMKLR1 are highly exaggerated in human and mouse adipocytes. This suggests that adipose tissue is a source and target for chemerin signaling [1]. Chemerin is a natural ligand for the chemerin receptor (ChemerinR), also known as chemokine receptor $1[2,3]$. Also, chemerin is a chemoattractant composed of 163 amino acids and synthesized as pre-prochemerin once secreted as an inactive precursor, called prochemerin [3,4]. The majority of circulating chemerin is in the form of inactive prochemerin and it has to be converted to bioactive chemerin isoforms (by proteolytic processes) for local biological activities [5]. Chemerin is excreted in the highest levels in the placenta, liver and white adipose tissue while it is excreted less in many tissues such as lung, brown fat tissue, heart, ovary, kidney, skeletal muscle and pancreas [3]. There is growing evidence that this newly discovered adipokine has been shown to play a role in adipogenesis and energy metabolism, including its role on obesity, Type 2 Diabetes Mellitus (T2DM), metabolic syndrome and cardiovascular diseases $[3,6,7]$. Determining circulating levels and monitoring the levels of chemerin adipokinin is of importance in relation to these diseases $[8,9]$.

It has been suggested that probiotics, which are defined as living microorganisms with beneficial effects on the health of the host cell, may play a role in the prevention of obesity by various mechanisms and treatment of many diseases such as T2DM [10]. Despite the fact that obesity is a multi-factor etiology, changes in intestinal microbiology have attracted attention in recent years [11]. Probiotic reinforcement may be a promising treatment for reversing dysbiosis-related changes in obesity and related diseases [12].

In this study, we aimed to evaluate the effects of probiotic supplementation of chemerin adipokines on serum levels and obesity markers in obese animal models produced by experimental high fat diet.

\section{Material and methods}

Within the scope of the study, 3 groups of experimental animals were formed. The first group was defined as the control group fed with the standard diet (Group 1), the second group as the group fed with the high fat diet (Group 2) and the third group as the group receive with probiotic capsule supplementation with a high fat diet (Group 3). After feeding the groups for a total of 12 week, in the obtained serum samples were examined with the effects of probiotic supplementation on HDL, LDL and total cholesterol which are indicators of lipid profile, leptin level which are the indicators of obesity, chemerin levels by used commercial ELISA (Rel Assay Diagnostic) kits. In addition, the weights of all rats were determined at the beginning of the study. Weights of all the rats in the groups will be weighed each week to monitor the obesity process and the relationship between the diets in different contents and Body Mass Index (BMI) were examined. The rats to be used in the study were obtained from Ondokuz Mayis University Experimental Animal Application and Research Center and the steps related to animal research are carried out in this center. 


\section{Results}

Initial weights of the rats in the control and study groups, weight changes at the beginning and after the probiotic reinforcement are shown in Table I.

TABLE I. MEAN VALUES OF MORPHOMETRIC PROPERTIES OF RATS

\begin{tabular}{|c|c|c|c|c|c|}
\hline & \multirow[t]{2}{*}{ Group 1} & \multirow[t]{2}{*}{ Group 2} & \multirow[t]{2}{*}{ Group 3} & \multicolumn{2}{|c|}{$\boldsymbol{P}$} \\
\hline & & & & $\begin{array}{l}\text { Group } \\
1-2-3\end{array}$ & $\begin{array}{l}\text { Group 2- } \\
3\end{array}$ \\
\hline Weight (g) & & & & & \\
\hline Baseline & $240,2 \pm 9,6$ & $254,6 \pm 16,0$ & $330,0 \pm 48,6$ & $0,013 *$ & $0,019 *$ \\
\hline Starter Probiotic & $283,8 \pm 11,0$ & $307,0 \pm 14,5$ & $400,5 \pm 65,0$ & $0,004 *$ & $0,014 *$ \\
\hline Post-Probiotic & $11,8 \pm 17,0$ & $339,6 \pm 19,6$ & $422,0 \pm 71,0$ & $0,009 *$ & $0,027 *$ \\
\hline Weight gain (g) (9.-12. week) & $23,2 \pm 7,8$ & $26,2 \pm 7,0$ & $10,0 \pm 27,2$ & 0,767 & 0,539 \\
\hline BMI $\left(\mathbf{g} / \mathrm{cm}^{2}\right)$ & & & & & \\
\hline Baseline & $0,41 \pm 0,01$ & $0,44 \pm 0,27$ & $0,57 \pm 0,08$ & $0,013 *$ & $0,016^{*}$ \\
\hline Starter Probiotic & $0,49 \pm 0,01$ & $0,53 \pm 0,02$ & $0,69 \pm 0,11$ & $0,004 *$ & $0,016^{*}$ \\
\hline Post-Probiotic & $\begin{array}{ll}0.54 & \pm \\
0,029 & \\
\end{array}$ & $0,54 \pm 0,02$ & $0,73 \pm 0,12$ & $0,009 *$ & $0,032 *$ \\
\hline
\end{tabular}

$p<0.05$

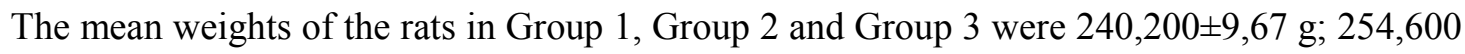
$\mathrm{g} \pm 16,00$ and $330,00 \pm 48,62 \mathrm{~g}$, respectively. After feeding with 8-week high-fat diet of the rats in group 2 and group 3, the weights were increased to $307,00 \pm 14,50 \mathrm{~g}$ and $400,50 \pm 65,039 \mathrm{~g}$, respectively. After 8 weeks of feding the BMI values of the rats in group 2 were reached from $0,44 \pm 0,27 \mathrm{~g} / \mathrm{cm}^{2}$ to $0.53 \pm 0$. $\mathrm{g} / \mathrm{cm}^{2}$, while the BMI values of the groups in group 3 were reached from $0,57 \pm 0,08 \mathrm{~g} / \mathrm{cm}^{2}$ to $0,69 \pm 0,11$ $\mathrm{g} / \mathrm{cm}^{2}(\mathrm{p}<0.05)$.

The average weight gains for 0-8th week and 9-12. week are shown in Fig 1.

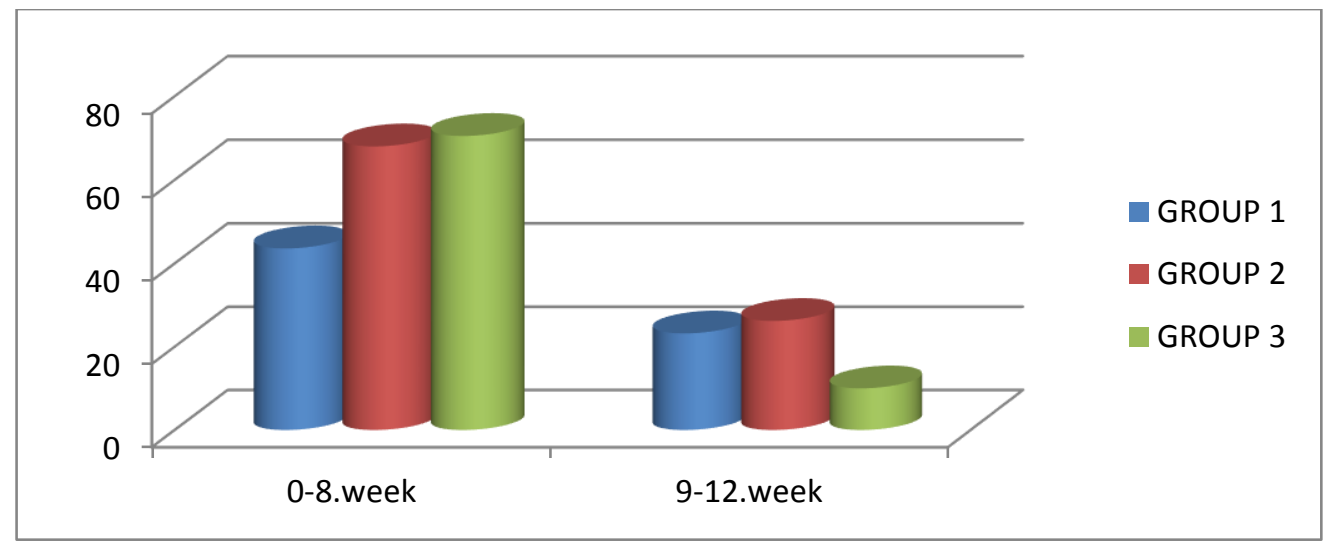

Figure 1. According to Groups Weight Gain from 0-12 Weeks

The weight gain in the group fed with probiotic supplementation was $10,00 \pm 27,2 \mathrm{~g}$ for 4 weeks and the weight gain for the group treated with high fat diet was $26,200 \pm 7,085 \mathrm{~g}(\mathrm{p}<0.05)$.

The BMI changes for the rats are shown in Fig 2. 


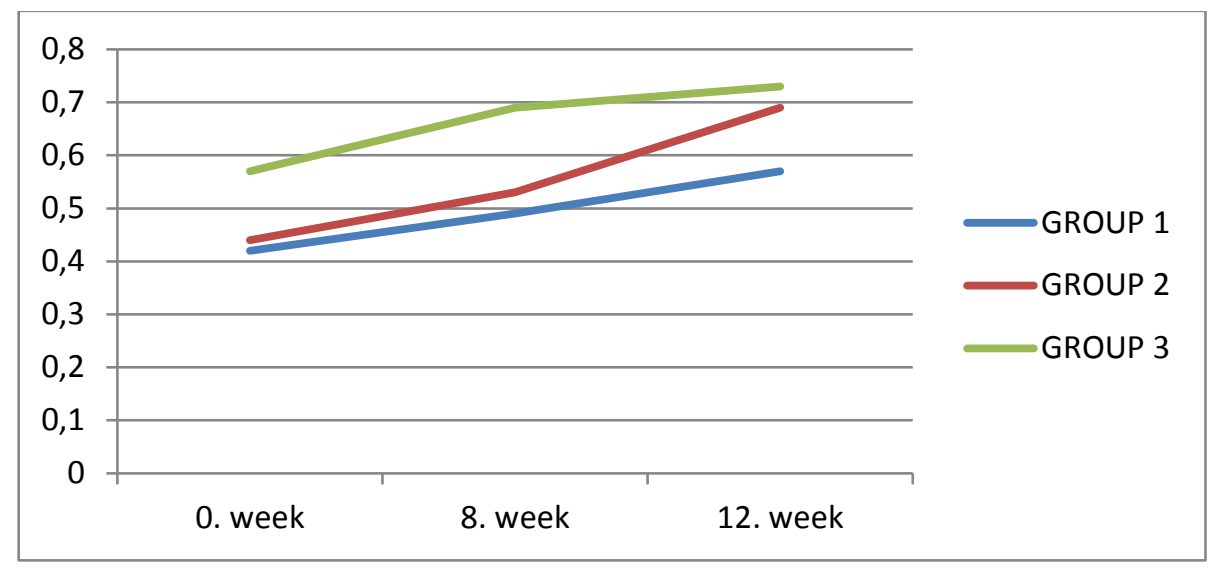

Figure 2. Changes in BMI for Groups from 0-12 Weeks

BMI changes in rats in group 2 are increasing rapidly, while changes in BMI in rats in group 3 tend to increase slowly after the start of probiotic supplementation.

Table II summarizes the laboratory findings of the study rats at baseline and after 12 weeks of feeding.

TABLE II. MEAN VALUES OF SERUM VALUES BY GROUPS

\begin{tabular}{|c|c|c|c|c|c|}
\hline & \multirow[t]{2}{*}{ Group 1} & \multirow[t]{2}{*}{ Group 2} & \multirow[t]{2}{*}{ Group 3} & \multicolumn{2}{|c|}{$\boldsymbol{P}$} \\
\hline & & & & $\begin{array}{c}\text { Group } \\
1-2-3\end{array}$ & $\begin{array}{c}\text { Group } \\
2-3\end{array}$ \\
\hline HDL $(\mu \mathrm{g} / \mathrm{ml})$ & & & & & \\
\hline Baseline & $21,69 \pm 0,73$ & $21,69 \pm 0,73$ & $21,50 \pm 0,68$ & 0,847 & 0,618 \\
\hline Final & $21,69 \pm 0,73$ & $21,00 \pm 2,63$ & $23,32 \pm 3,76$ & 0,663 & 0,325 \\
\hline LDL $(\mu \mathrm{g} / \mathrm{ml}$ & & & & & \\
\hline Baseline & $31,50 \pm 4,02$ & $31,50 \pm 4,02$ & $32,15 \pm 4,33$ & 0,965 & 0,907 \\
\hline Final & $31,50 \pm 4,02$ & $43,12 \pm 11,77$ & $31,87 \pm 2,89$ & 0,083 & 0,059 \\
\hline $\begin{array}{l}\text { Total Cholesterol } \\
(\mathrm{mmol} / \mathrm{L})\end{array}$ & $13,74 \pm 2,90$ & $13,74 \pm 2,90$ & $12.52 \pm 1.1$ & 0,847 & 0,618 \\
\hline $\begin{array}{r}\text { Baseline } \\
\text { Final }\end{array}$ & $13,74 \pm 2,90$ & $22,30 \pm 3,99$ & $14,87 \pm 3,00$ & $0,004 *$ & 0,447 \\
\hline Leptin (ng/L) & & & & & \\
\hline Baseline & $2069,34 \pm 121,60$ & $2069,34 \pm 121,6$ & $2069,34 \pm 121,6$ & 0,977 & 0,827 \\
\hline Final & $2069,34 \pm 121,60$ & $\begin{array}{c}0 \\
2165,34 \pm 80,88\end{array}$ & $\begin{array}{c}0 \\
2026,65 \pm 106,7 \\
0\end{array}$ & 0,149 & 0,058 \\
\hline Chemerin (ng/mL) & & & & & \\
\hline Baseline & $76,78 \pm 33,77$ & $76,78 \pm 33,77$ & $70,37 \pm 35,32$ & 0,959 & 0,803 \\
\hline Final & $76,78 \pm 33,77$ & $120,42 \pm 19,68$ & $116,07 \pm 4,25$ & $0,028 *$ & 0,172 \\
\hline
\end{tabular}

$p<0.05$

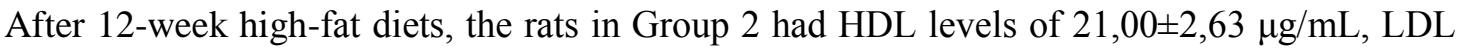
levels of $43,12 \pm 11,77 \mu \mathrm{g} / \mathrm{mL}$ and total cholesterol levels of $22,31 \pm 3,99 \mathrm{mmol} / \mathrm{L}$. The mean HDL, LDL and total cholesterol values of the rats in Group 3 after supplementation with probiotics were 23,32 $\pm 3,76$ $\mu \mathrm{g} / \mathrm{mL}, 31,87 \pm 2,89 \mu \mathrm{g} / \mathrm{mL}$ and $14,87 \pm 3,00 \mathrm{mmol} / \mathrm{L}$, respectively. There was no significant difference between groups in terms of HDL and LDL, but a significant difference was found between total 
cholesterol values ( $\mathrm{p}<0.05)$. After 12 weeks of feeding, the mean values of the chemerin values of the groups were 24,26 $\pm 19,39 \mathrm{ng} / \mathrm{mL}$ (Group 1); 71,53 $\pm 35,23 \mathrm{ng} / \mathrm{mL}$ (Group 2); 60,35 $\pm 9,32 \mathrm{ng} / \mathrm{mL}$ (Group 3).There was no significant difference between the initial chemerin values of the groups, but the difference between the mean values of the chemerin values after 12 weeks of feeding was found to be statistically significant $(\mathrm{p}<0.05$ ). There was no statistically significant difference between leptin values obtained at baseline and after 12 weeks feeding in groups.

The mean leptin and chemerin values of Group 1, Group 2 and Group 3 are shown in Fig 3.
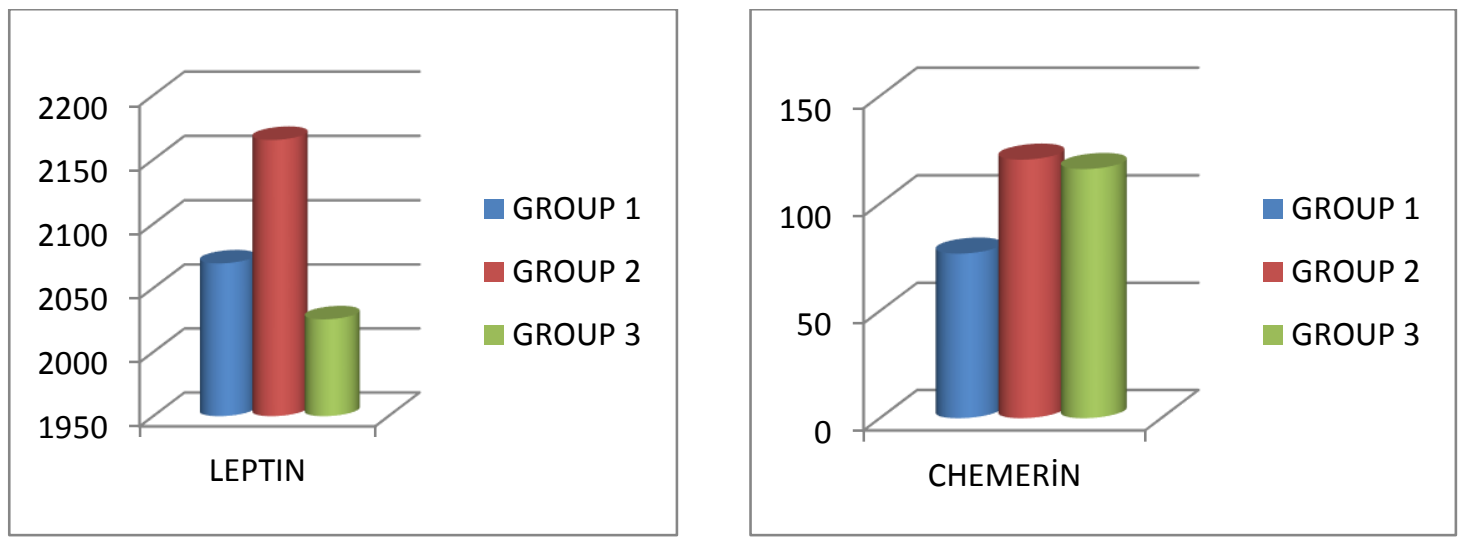

Figure 3. Mean Values of Leptin and Chemerin for The 12th Week According to The Groups

\section{Discussion}

It has been determined that the probiotic supplementation performed without any weight loss method has significant changes in both weight gain and metabolic parameters. Studies investigated in support of the association between adiposity and serum chemerin levels have observed significant reductions in serum chemerin levels compared to obese individuals who did not enter weight loss interventions (calori restriction or bariatric surgery) in individuals who various weight loss procedures [7,13,14]. Fatima et al. [15] also reported that circulating chemerin levels were significantly higher in obese subjects with BMI $>25 \mathrm{~kg} / \mathrm{m}^{2}$ than subjects with BMI $<25 \mathrm{~kg} / \mathrm{m}^{2}$. In our study, chemerin levels of normal rats were found to be lower than those of obese rats.

In humans, serum chemerin concentration is significantly higher in the BMI and waist circumference than in normal weight patients [16]. In our study, a positive correlation was found between the BMI values and the chemerin levels of the rats.

When examinated of experimental animal studies suggests that probiotic supplementation results in similar results with our study on body weight and metabolic parameters. In a study evaluating changes in high fat diets-related adiposity, intestinal microbiota and serum metabolite levels in rats fed a balanced or high fat diet with and without probiotic for 8 weeks; it has been determined that probiotic supplementation modulates morphometric and metabolic parameters effectively and reduces body weight [11].

Kang et al. [17] investigated the effects of probiotic supplementation on weight loss; rats were fed on a high carbohydrate diet for 12 weeks and received probiotic supplementation twice daily. This study 
in which changes in body weight and metabolic parameters are observed, shows that probiotics can prevent weight gain, improve metabolic parameters, and be an alternative method of treating obesity. In monosodium glutamate (MSG) -induced obese rats, probiotic supplementation similarly improves body weight and TC, LDL and HDL levels [18].

Studies in the literature regarding the effect of probiotics on the serum level of chemerin adipokine are not sufficient and our results are of importance in terms of the reduced effect on chemerin adipokine levels.

\section{Conclusion}

As a result; this study showed that obese rats reduced the weight gain of probiotic supplementation without calorie restriction, positive effects on BMI and chemerin adipokine serum levels. The next step of our study is to increase the number of rats in the experimental groups and extend the probiotic supplementation period to achieve more comprehensive results.

\section{References}

[1] Booth, A., Magnuson, A., Fouts, J., Foster, M. Adipose tissue, obesity and adipokines: role in cancer promotion, Horm Mol Biol Clin Invest, 21(2015),1, pp. 57-74.

[2] Roh, S., Song, S., Choi, K., Katoh, K., Wittamer, V., Parmentier, M., Sasaki, S. Chemerin-A new adipokine that modulates adipogenesis via its own receptor, Biochemical and Biophysical Research Communications, 362 (2007), pp. 1013-18.

[3] Rourke, JL., Dranse, HJ., Sinal, CJ. Towards an integrative approach to understanding the role of chemerin in human health and disease, Obes, 14 (2013),3, pp. 245-62.

[4] Dupont, J., Pollet-Villard, X., Reverchon, M., Mellouk, N., Levy, R. Adipokines in human reproduction, Horm Mol Biol Clin Invest, 24 (2015),1, pp. 11-24.

[5] Ernst, MC., Sinal, CJ. Chemerin: at the crossroads of inflammation and obesity, Trends in Endocrinology and Metabolism, 21 (2010),11.

[6] Goralski, KB., McCarthy, TC., Hanniman, EA. et al. Chemerin, a novel adipokine that regulates adipogenesis and adipocyte metabolism, J Biol Chem, 282 (2007), 38, pp. 28175-88.

[7] Chang, SS., Eisenberg, D., Zhao, L. et al. Chemerin activation in human obesity, Obesity, 27 (2016), 7, pp. 1522-9.

[8] Bauer, S., Bala, M., Kopp, A. et al. Adipocyte chemerin release is induced by insulin without being translated to higher levels in vivo, Eur J Clin Invest, 42 (2012), 11, pp. 1213-20.

[9] Li, Y., Shi, B., Li, S. Association between serum chemerin concentrations and clinical indices in obesity or metabolic syndrome: a meta-analysis, PLoS One, 9 (2014), 12, e113915. 
[10] Sánchez, B., Delgado, S., Blanco-Míguez, A. et al. Probiotics, gut microbiota, and their influence on host health and disease, Molecular nutrition \& food research, 61 (2017),1.

[11] Shin, J. H., Nam, M. H., Lee, H., Lee, J. S., Kim, H., Chung, M. J., \& Seo, J. G. Amelioration of obesity-related characteristics by a probiotic formulation in a high-fat diet-induced obese rat model, European Journal of Nutrition, 2017, pp. 1-10.

[12] Moya-Perez, A., Romo-Vaquero, M., Tomas-Barberan, F., Sanz, Y., \& García-Conesa, M. T. Hepatic molecular responses to Bifidobacterium pseudocatenulatum CECT 7765 in a mouse model of diet-induced obesity. Nutrition, Metabolism and Cardiovascular Diseases, 24 (2014), 1, pp. 57-64.

[13] Ress, C., Tschoner, A., Engl, J., Klaus, A., Tilg, H., Ebenbichler, CF., Patsch, JR., Kaser, S. Effect of bariatric surgery on circulating chemerin levels, Eur J Clin Invest, 40 (2010), 3, pp. 277-80.

[14] Chakaroun, R., Raschpichler, M., Klöting, N., Oberbach, A., Flehmig, G., Kern, M., Schön, MR., Shang, E., Lohmann, T., Dreßler, M., Fasshauer, M., Stumvoll, M., Blüher, M. Effects of weight loss and exercise on chemerin serum concentrations and adipose tissue expression in human obesity, Metabolism Clincal and Experimental, 61 (2012), pp. 706-14.

[15] Fatima, SS., Bozaoglu, K., Rehman, R., Alam, F., Memon, AS. Elevated Chemerin Levels in Pakistani Men: An Interrelation with Metabolic Syndrome Phenotypes, PLoS ONE, 8 (2013), 2, e57113.

[16] Thomas, S., Kratzsch, D., Schaab, M., Scholz, M., Grunewald, S., Thiery, J., Paasch, U., Kratzsch, J. Seminal plasma adipokine levels are correlated with functional characteristics of spermatozo, Fertil Steril, 99 (2013), pp. 1256-63.

[17] Kang, J. H., Yun, S. I., \& Park, H. O. Effects of Lactobacillus gasseri BNR17 on body weight and adipose tissue mass in diet-induced overweight rats, The Journal of Microbiology, 48 (2010),5, pp. 712-14.

[18] Kobyliak, N., Falalyeyeva, T., Beregova, T., \& Spivak, M. Probiotics for experimental obesity prevention: focus on strain dependence and viability of composition, Endokrynologia Polska, (2015). 